\title{
Regulation of GH-Releasing Hormone Receptors
}

\author{
MAKOTO SATO, TOMOYO OHYAMA, AND JIRO TAKAHARA \\ First Department of Internal Medicine, Kagawa Medical University, Kagawa 761-07, Japan
}

SECRETION and gene expression of GH are controlled by hypothalamic GH-releasing hormone (GRH) which acts through a $G$ protein-coupled receptor, GRH receptor, resulting in activation of cyclic AMP and A-kinase systems in the somatotropes [1]. Many humoral factors affect $\mathrm{GH}$ responses to GRH [1] and some of their effects may be caused by qualitative and quantitative changes in GRH receptors. Glucocorticoids are one of the most important factors modifying GH secretion and gene expression. Many lines of evidence indicated that glucocorticoids stimulate $\mathrm{GH}$ secretion and gene expression at least by their acute effects [25]. It has also been reported that dexamethasone (Dex) increases GRH binding sites in the rat pituitary membrane [6]. We therefore questioned whether Dex regulates GRH receptor gene expression, since most of the biological effects of glucocorticoids are attributed to their genomic actions on target genes in many types of cells [7].

To investigate GRH receptor gene expression at mRNA levels, a highly-sensitive method is required, because GRH receptor mRNA content is very low even in the anterior pituitary [8]. Conventional Northern blot analysis of total RNA in the pituitary tissue of a single rat fails to detect this lowabundant mRNA. Polymerase chain reaction (PCR) is extremely sensitive and quantitative PCR is useful for examining the regulation of GRH receptor mRNA levels. We previously established a competitive reverse transcription (RT)-PCR method $[9,10]$. In the present study, we examined the

Correspondence to: Dr. Makoto SATO, First Department of Internal Medicine, Kagawa Medical Universtiy, 1750-1, Ikenobe, Miki-cho, Kita-gun, Kagawa 761-07, Japan

Key words: GH-releasing hormone, Receptor, Glucocorticoid, Dexamethasone, Polymerase chain reaction effects of Dex on GRH receptor mRNA levels by using the competitive RT-PCR method. In vitro, the effects of Dex on GRH receptor mRNA levels were examined with the primary culture system of rat anterior pituitary cells. In vivo, rats were exposed to Dex or glucocorticoid deficiency due to adrenalectomy, and GRH receptor mRNA levels were examined in the anterior pituitary tissue.

\section{Materials and Methods}

Competitive RT-PCR method was used to quantify GRH receptor mRNA levels as previously described [10]. Briefly, total RNA was extracted from rat anterior pituitary tissues or cultured rat anterior pituitary cells. The stock competitor (recombinant RNA) was diluted from $10 \mathrm{pg}$ to 10 fg by 10 -fold serial dilutions. Five hundred nanograms of each total RNA and diluted competitor were added to the same microtube and reverse transcribed into cDNA with random primers. Thirty cycles of PCR were carried out in a thermal cycler based on a step program of $94^{\circ} \mathrm{C}$ for $80 \mathrm{sec}, 49^{\circ} \mathrm{C}$ for $80 \mathrm{sec}, 72{ }^{\circ} \mathrm{C}$ for $80 \mathrm{sec}$, followed by a 15 -min extension at $72{ }^{\circ} \mathrm{C}$. PCR products were electrophoresed on an $1.5 \%$ agarose gel containing ethidium bromide and photographed. Signal intensities of each product were quantified with an image analyzer. The concentration of GRH receptor mRNA was calculated by regression analyses of samples and competitors.

The primary culture system of rat anterior pituitary cells was prepared as previously described [11]. The cells were treated with Dex 4 days after preparation and the dose- and time-dependent effects of Dex on GRH receptor mRNA levels were examined with total RNA extracted from the treated 
cells. In a separate series of experiments, a glucocorticoid receptor-specific antagonist, RU38486 (Roussel UCLAF, Paris, France), was added to the cells in the presence of Dex. For in vivo studies, male adult Wistar rats were used. Dex was administered to the rats by ip injection and they were killed by decapitation $24 \mathrm{~h}$ after the single injection. Total RNA was extracted from rat anterior pituitary tissues to examine GRH receptor mRNA levels. In the next series of experiments, rats underwent adrenalectomy to remove endogenous glucocorticoids. Vehicle and Dex were administered to the glucocorticoid-deficient animals. Anterior pituitary tissues were obtained 3 days after surgery to examine GRH receptor mRNA levels. Statistical comparisons were made by one-way analysis of variance and Student's $t$ test, with $P<0.05$ being considered significant.

\section{Results}

Cultured rat anterior pituitary cells were treated with Dex at several concentrations for $24 \mathrm{~h}$. GRH receptor mRNA levels were significantly increased by Dex at a concentration of $5 \mathrm{nM}$ and the maximal effect was noted at $25 \mathrm{nM}$ (Fig. 1). Time-course effects of Dex were examined in the next series of experiments. The concentration of Dex was adjusted to $5 \mathrm{nM}$ in these experiments. GRH receptor mRNA levels were not altered by $2-h$ incubation with Dex, but the 6-h incubation significantly increased GRH receptor mRNA levels in the cultured rat anterior pituitary cells (Fig. 2). This stimulatory effect of Dex persisted until at least $24 \mathrm{~h}$ after treatment. A glucocorticoid receptor specific antagonist, RU 38486, significantly inhibited Dex-induced increase in GRH receptor mRNA levels (Fig. 3).

In the first series of in vivo studies, a single ip injection of Dex had not significantly altered pituitary GRH receptor mRNA levels $24 \mathrm{~h}$ after the injection (Fig. 4). Changes in GRH receptor mRNA levels were similar when much lower doses of Dex were used in the same protocol. Even longer exposure to a high dose $(200 \mu \mathrm{g} / \mathrm{rat})$ of Dex for up to 3 weeks did not significantly alter pituitary GRH receptor mRNA levels. Figure 5 shows the effects of adrenalectomy on pituitary GRH receptor mRNA levels in rats. GRH receptor mRNA levels were significantly decreased 3 days after adrenalectomy,

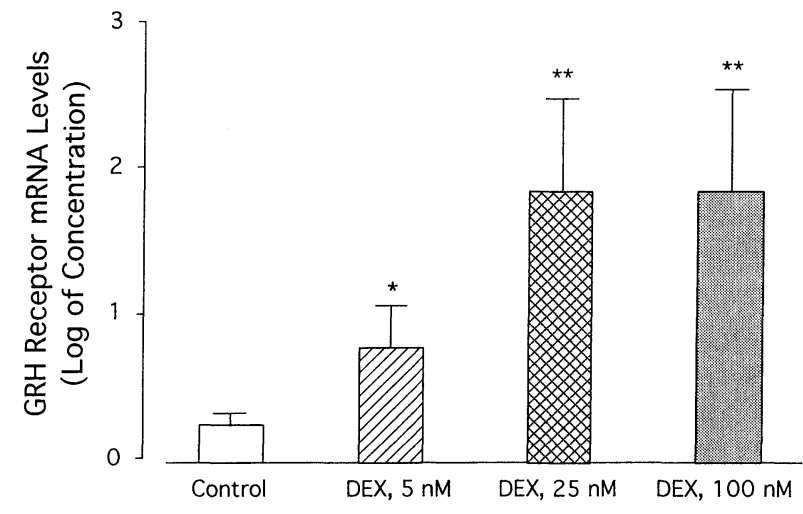

Fig. 1. Dose-response effects of dexamethasone (DEX) on GRH receptor mRNA levels in cultured rat anterior pituitary cells. Redrawn from figure 3 by Tamaki et al. (J Neuroendocrinol 8: 475-480, 1996).

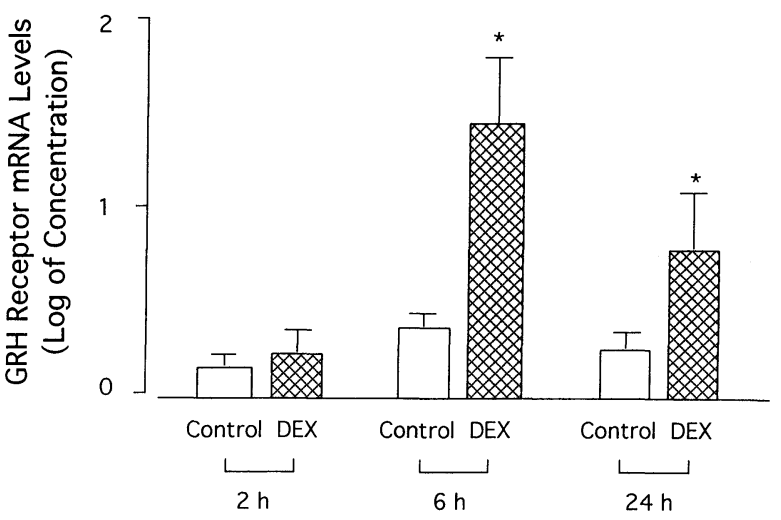

Fig. 2. Time-course effects of dexamethasone (DEX) on GRH receptor mRNA levels in cultured rat anterior pituitary cells. Redrawn from figure 2 by Tamaki et al. (J Neuroendocrinol 8: 475-480, 1996).

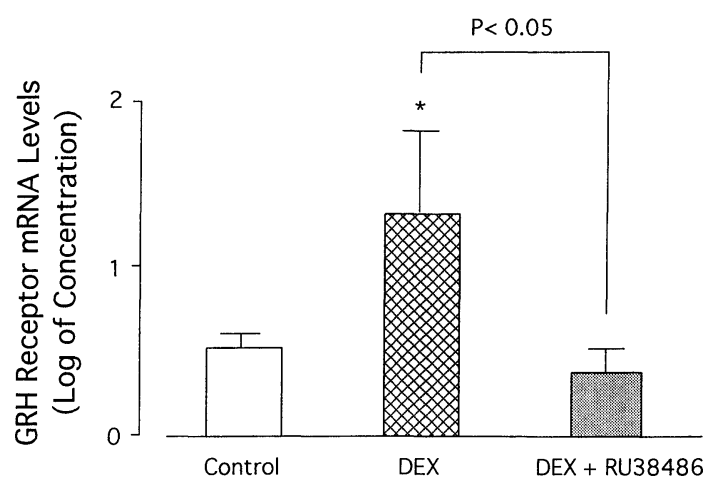

Fig. 3. Effects of RU 38486 on dexamethasone (DEX)-induced increase in GRH receptor mRNA levels in cultured rat anterior pituitary cells. Redrawn from figure 4 by Tamaki et al. (J Neuroendocrinol 8: 475-480, 1996). 


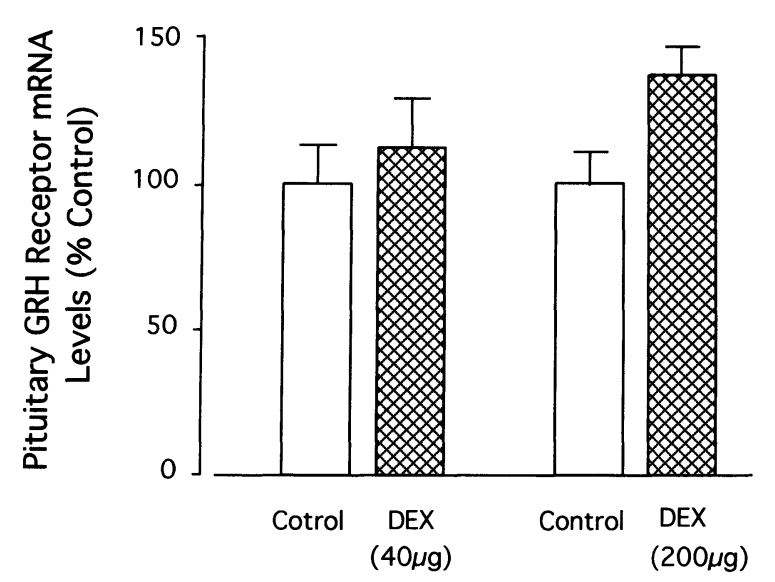

Fig. 4. Effects of dexamethasone (DEX) injection on pituitary GRH receptor mRNA levels in rats. DEX (40 or $200 \mu \mathrm{g} / \mathrm{rat}$ ) was administered to male rats by ip injection for 3 days. Six animals were used in each group.

but when the glucocorticoid-deficient rats received a daily administration of $50 \mu \mathrm{g}$ of Dex for 3 days, pituitary GRH receptor mRNA levels returned to normal (Fig. 5).

\section{Discussion}

Our in vitro studies indicated that Dex stimulates GRH receptor mRNA expression in rat somatotropes. This effect was dose- and timedependent, and blocked by the glucocorticoid receptor specific antagonist, RU 38486. These findings suggest that Dex stimulates the transcriptional activity of the GRH receptor gene through the glucocorticoid receptors. Glucocorticoids activate many genes at the transcriptional level [7]. Ligand-activated GC receptor homodimers bind to characteristic DNA response elements (glucocorticoids response elements: GREs) [12]. Since there are no GREs in the promoter region of rat GRH receptor gene (personal communication), direct interaction between glucocorticoids and GRH receptor genes seems unlikely in Dex-induced enhancement of GRH receptor mRNA levels. Instead, glucocorticoids may enhance the stability of GRH receptor mRNAs as demonstrated in several other genes $[13,14]$. In the present study, stimulatory actions of Dex in GRH receptor mRNA levels were

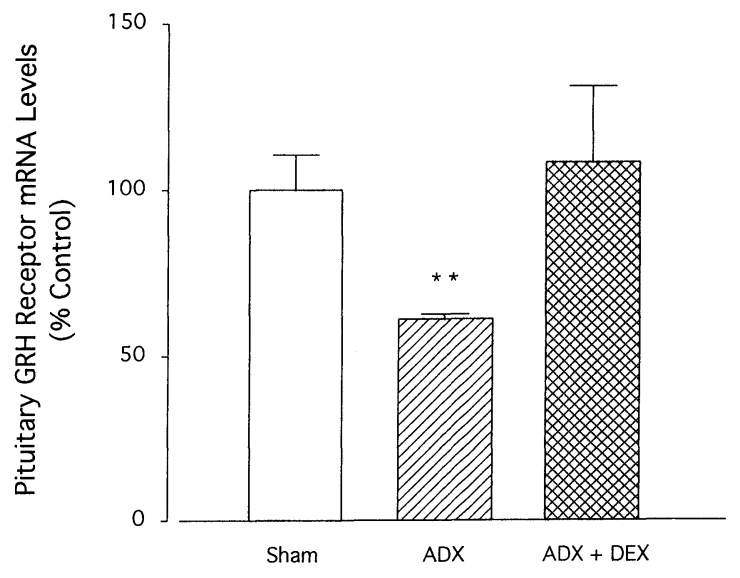

Fig. 5. Effects of adrenalectomy (ADX) and dexamethasone (DEX) replacement on pituitary GRH receptor mRNA levels in rats. Shamoperated (Sham) and adrenalectomized rats were killed 3 days after the operation. DEX (50 $\mu \mathrm{g} / \mathrm{rat}$ ) was administered to adrenalectomized rats by ip injection for 3 days. Five animals were used in each group. ${ }^{* *} P<0.01 v s$. Sham.

delayed, requiring more than $2 \mathrm{~h}$ at least. This also suggests that the Dex-induced increase in GRH receptor mRNA levels might be due to indirect effects on the stability of GRH receptor mRNA.

Administration of Dex to the rats did not cause a significant increase in GRH receptor mRNA levels. Although a high dose of Dex $(200 \mu \mathrm{g} / \mathrm{rat})$ was administered to the rats daily for a prolonged period (up to 3 weeks), pituitary GRH receptor mRNA levels were not significantly increased. These results indicate that pituitary GRH receptor mRNA levels are less affected by glucocorticoid excess in vivo. A considerable number of reports have previously shown that the effects of glucocorticoids on the GH-regulatory system appear to be different, sometimes even opposite, on comparison of in vitro and in vivo results [15]. Hypothalamic modification by GRH and somatostatin, and metabolic influence may modify glucocorticoid actions, and we do not preclude the possibility that the doses and ways of Dex administration might be responsible for the lack of its stimulatory effect on GRH receptor mRNA levels in vivo.

On the other hand, GRH receptor mRNA levels were significantly lowered in glucocorticoiddeficient rats after adrenalectomy. Furthermore, replacement of Dex normalized the pituitary GRH 
receptor mRNA levels in these animals. Seifert et al. [6] previously reported that adrenalectomy decreased GRH binding sites in rat anterior pituitary membrane homogenates. Taken together, these findings imply that physiological levels of endogenous glucocorticoids are necessary for normal expression of pituitary GRH receptors at both mRNA and protein levels. This might, at least partly, explain the pathogenesis of GH impairment observed in patients with glucocorticoid deficiency. Giustina et al. [16] have reported that $\mathrm{GH}$ responses to insulin-induced hypoglycemia and arginine infusion are suppressed in patients with isolated ACTH deficiency. Since such provocation tests appear to act through the stimulation of hypothalamic GRH secretion [1], GH response to GRH appears impaired in glucocorticoid-deficient patients.

In conclusion, our study indicates that Dex enhances GRH receptor gene expression through the glucocorticoid receptors in rat somatotropes. Endogenous glucocorticoid seems therefore to play an important role in regulating GRH receptor gene expression in the rat pituitary.

\section{References}

1. Frohman LA, Downs TR, Chomczynski P (1992) Regulation of GH secretion. Front Neuroendocrinol 13: 344-405.

2. Bridson WE, Kohler PO (1970) Cortisol stimulation of growth hormone production by human pituitary tissue in culture. J Clin Endocrinol Metab 30: 538540 .

3. Adams EF, Brajkovich IE, Mashiter K (1981) Growth hormone and prolactin secretion by dispersed cell cultures of human pituitary adenomas: Long term effects of hydrocortisone, estradiol, insulin, 3,5,3'triiodothyronine and dexamethasone on $\mathrm{GH}$ secretion in vitro. J Clin Endocrinol Metab 53: 381386.

4. Vale W, Vaughan J, Yamamoto G, Spiess J, Rivier J (1983) Effects of synthetic human pancreatic (tumor) GH releasing factor and somatostatin, triiodothyronine and dexamethasone on $\mathrm{GH}$ secretion in vitro. Endocrinology 112: 1553-1555.

5. Evans RM, Birnberg NC, Rosenfeld MG (1982) Glucocorticoid and thyroid hormones transcriptionally regulate growth hormone gene expression. Proc Nat Acid Sci USA 79: 7959-7663.

6. Seifert H, Perrin M, Rivier J, Vale W (1985) Growth hormone-releasing factor binding sites in rat anterior pituitary membrane homogenates: Modulation by glucocorticoids. Endocrinology 117: 424-426.

7. Beto M (1989) Gene regulation by steroid hormones. Cell 56: 335-344.

8. Matsubara S, Sato M, Mizobuchi M, Niimi M, Takahara J (1995) Differential gene expression of growth hormone (GH)-releasing hormone (GRH) and GRH receptor in various rat tissues.
Endocrinology 136: 4147-4150.

9. Sato M, Mizobuchi M, Murao K, Tamaki M, Takahara J (1994) Simple quantitative reverse transcribed-polymearase chain reaction (RT-PCR) method involving recombinant RNA generated by a false-priming PCR product. J Biochem 116: 11981201.

10. Tamaki M, Sato M, Matsubara S, Wada $Y$, Takahara J (1996) Dexamethasone increases growth hormone (GH)-releasing hormone (GRH) receptor mRNA levels in cultured rat anterior pituitary cells. $J$ Neuroendocrinol 8: 475-480.

11. Sato $M$, Takahara J, Fujioka $Y$, Niimi N, Irino $S$ (1988) Physiological role of growth hormone (GH)releasing factor and somatostatin in the dynamics of $\mathrm{GH}$ secretion in adult male rat. Endocrinology 123: 1928-1933.

12. Freedman LP (1992) Anatomy of the steroid receptor zinc finger region. Endocr Rev 13: 129-145.

13. Pack I, Axel R (1987) Glucocorticoids enhance stability of human growth hormone mRNA. Mol Cell Biol 7: 1496-1507.

14. Dean C, Newly RF, Bourgeois S (1988) Regulation of fibronectin biosynthesis by dexamethasone, transforming growth factor $\beta$ and cAMP in human cell lines. J Cell Biol 106: 2159-2170.

15. Giustina A, Wehrenberg WB (1992) The role of glucocorticoids in the regulation of growth hormone secretion. Trends Endocrinol Metab 3: 306-311.

16. Giustina A, Fomanelli G, Candrina R, Giustina G (1989) Growth hormone deficiency in patients with idiopathic adrenocorticotropin deficiency resolves during glucocorticoid replacement. J Clin Endocrinol Metab 68: 120-124. 